\title{
Coping Patterns of Sero Positive Person: A Qualitative Study
}

\author{
P. K. Rai ${ }^{1 *}$, Dr. Sanjita Gupta ${ }^{2}$, Rituraj $^{3}$
}

\section{ABSTRACT}

This paper is based on qualitative analysis of sero positive persons, copping strategies based on semi structured interview schedule, narrative analysis and in depth analysis. Eight case histories have been analysed, On the basis of different coping strategies and world views. Self narrative of a positive person who has been transformed in to a global AIDS counsellor, married to a sero negative woman, has been discussed in detail. Excerpt from his interview has also been portrayed. Case histories have been analysed and labelled in to dominant coping strategies like venting of emotions, positive restructuring and growth, cognitive reappraisal etc. Positive self regulation of emotional pain has also been depicted. These analyses have relevance for psychological counselling for positive persons struggling to overcome the distress and want to lead adaptive life in their families. It portrays that positive persons have immerse capabilities to cope with adversities and positive self transformation.

Keywords: HIV/AIDS, Positive Living, Coping and Adjustment, Cognitive Restructuring

Life is not always bed of roses it is also beset with tragedies and traumas of varied nature, viz., bereavement, life threatening diseases, loss of material possessions and relationships, etc. People not only learn to live with their losses, but many emerge enriched and invigorated. How people handle their emotional distress is an area of research rife with many possibilities of growth, selfenhancement or decay. The main objective of this part of study was to augment understanding of how people handle their emotional setbacks and to trace the process of healing. The study also examined the reconfiguration of self as adaptation progresses.

Emotional distress refers to a feeling of loss and vulnerability, in the face of major life crises. It is akin to an experience of losing a part of oneself. It includes in its gamut a feeling of brokenness and loss of control. Emotional distress is a natural consequence of living in this world that gets complicated as a result of a tendency to avoid or deny painful feelings. Clinical interventions aims at working through distress is a necessary task to induce changes in the inner self and ultimately in the ability to cope with life in healthier and more satisfying ways (Bradshaw, 1990). Taylor (1997) has called attention to a profound sense of isolation meaninglessness, hopelessness and despair, as major accompaniments of emotional distress.

\footnotetext{
${ }^{1}$ Prof. \& Head, Dept. Of Psychology, Doctor Harisingh Gour Vishwavidyalaya, Sagar, Madhya Pradesh

${ }^{2}$ Former Research Scholar, Dept. Of Psychology, Dr. Harisingh Gour Vishwavidyalaya, Sagar, Madhya Pradesh

${ }^{3}$ Research Scholar, Dept. Of Psychology, Doctor Harisingh Gour Vishwavidyalaya, Sagar, Madhya Pradesh *Corresponding Author

(C) 2015 I P Rai, S Gupta, Rituraj; licensee IJIP. This is an Open Access Research distributed under the terms of the Creative Commons Attribution License (http://creativecommons.org/licenses/by/2.0), which permits unrestricted use, distribution, and reproduction in any Medium, provided the original work is properly cited.
} 
According to him, emotional setback isolates a person from the flow of contemporary events. One may often be ridden with the feeling of being abandoned and having been left alone. Bakan (1968) has focused on intimate relationships and considers emotional distress as a loss of familial world, which evokes fear of annihilation. Jain (1994) has depicted in his work some of the emotions that are construed within the Indian cultural milieu. Mishra (2002) has further examined emotional experiences within the social constructionist framework. Accordingly, the experience of emotional set backs are interwoven in a matrix of meanings, identities and relationships, specific to a particular culture.

This study is based on self narratives and case history interview of sero positive persons living in Mumbai.

A qualitative analysis was done to enrich understanding of how people work through emotional distress which culminates in self transformation and healing or other adjustive reactions. Direct narration of persons, who had undergone through major life crisis was generated and analyzed, the path traversed in arriving a self healing, or reaching a workable adjustment with the situation.

The study also examined reconfiguration of self as adjustment proceeds. There is always ambivalence in life. People see their heart shattered but reconfiguration takes place and a compromise is a seemingly uncompromising situation.

\section{The Case History Analysis on Psychological Concepts Related With Coping}

Analysis will be made on the basis of psychological mechanisms involved in the process of adjustment with life threatening disease like HIV/AIDS. While analyzing the case history following Psychological mechanisms will be taken in to account, Emotional Self Regulation; forgiveness; Catharsis (Chimney sweeping or Ventilation); Social-support or seeking information; Direct Action; Strategies of distraction, Escape or Avoidance, Personal Growth, Positive Thinking and Restructuring etc.

\section{Emotional Regulation}

Emotional Regulation may be perceived as an experience of an inner sense of well-being, harmony, balance, and peace. It is a process through which the harmony between mind, body and spirit is restored. It would involve a reconstruction of one's reality, Perceived change in emotional perspective, and broadening of one's horizons. Thus regulation does not change the life conditions causing emotional distress, but engenders hope, acceptance, release of trapped psychic energy, resolution of internal conflicts and new insights (Kakar,1982). Bonanno (2001) has discussed the issue of Emotional self Regulation for adaptation to the ongoing daily life situation and for acute stressful events live acute illness. He has discussed three form of Emotional self regulations- could Regulations, Anticipatory Regulation and Exploratory Regulations. When emotional homeostasis is not achieved people use control regulations live emotional dissociation, suppression, expression or laughter. But when the emotional homeostasis 
or balance is not maintained, people in order to cope with the situation engage in or various activities like seek out to avoid people places situations, or acquire new skills to cope with the situations, make cognitive reappraisal, write about the emotion, talk about the emotion, express the emotion or resort to laughter. In the third state when the people are able to maintain emotional homeostasis, they would like to actively engage in productive and constructive pursuits and also engage in activities to learn more about emotions.

\section{Emotional Ventilation}

Siegel (1991) says "When you put your feelings outside, you may heal inside and you will certainly heal your life, if not your disease for emotional repression prevents the healing system from responding as a unified entity to threats from inside or outside”. Anger, anxiety, depression, fear and many other feelings are unhealthy only if they remain buried inside, unexpressed and not dealt with. When one goes beyond one's surface emotions and begins to acknowledge one's real fears, one can break through the resentments and disappointments one holds, and herein begins the process of Emotional Regulation in this sense, it means one's ability to become "whole" again, to gather together the many fragmented pieces of one's life and make peace inside. True regulation means one's ability to discover oneself and one's sense of purpose and meaning in this life. This is a process and difficult awesome but at the same time transcendence also.

\section{Role of Forgiveness}

If one forgives a person a man frees himself from the resistance, he encounters simmering from retaliation and vengeance. If one is true to himself a friend of himself, acknowledges his failure and mistakes and have courage to disclose himself, this divulgence cleans his heart psychologically and frees himself from any anatomical pressure on heart (like speedy breathing) or brain (like stroke).

One cannot deceive himself, if one cannot forgive himself he cannot forgive other in true sense. If he does it is a show of to others and feels more resistance from either. In incessant tears burst when person forgives and makes a man light and regulated.

The emotional self regulation is to be in touch with emotions, to see them as you are witnessing them. The crux of any spiritual practice lies primarily in developing 'Sakschi Bhava'.

Taylor (1997) contends that forgiveness forms the very basis of healing. One cannot "pretend" to forgive oneself or others. One needs to courageously go within and feel one's hurt and sadness and grieve one's losses; acknowledge one's failures and mistakes, even when one may feel they were justified or deserved; forgive oneself through the hard and difficult path of self-disclosure and honesty. But this paradox is reality of life we wish to die but at the same time wish to live. One can find one's true strength and reality strength acknowledging and accepting one's own humanity, one's vulnerabilities, and one's limitations (Lama, 1992). The healing process (of any 
type) is an emotionally charged experience (Frank \&Frank, 1984), and the salience of any social or spiritual practice lies primarily in their ability to elicit healing emotions.

When one forgives others he frees himself from all resistance towards others and in true sense by forgiving others one fills heart from love and compassion and thus positive energy to function.

\section{Self Disclosure}

Scientific evidence for the healing power of self disclosure of emotions and honest selfexamination comes from the work of James Pennebaker (1988). He found that writhing about traumatic experiences for as little as 15 minutes a day for 4 days can reduce physician visits for illness, improve serum immune function and enhance work performance up to 6 month time. That is to say, that sharing one's true feelings and needs heaps one to unlock the power of one's healing system. Why does this disclosure improve one's health and trigger one's healing system? The disclosure is a deep and sometimes painful exploration of one's deepest thoughts and feelings involved in the traumatic event. Somehow, when one moves one's disturbing thoughts, feelings, fears, hurts, disappointments and resentments onto paper, one takes that energy "out of our bodies" in an appropriate manner (i.e. not dumping it onto others or kicking the cat ) and begin to "free up" one's own internal healing energies.

The case studies analysis is based on narrative approach to illuminate the process of adjustment to sero positive status. Narratives are life stories. Narratives are about the past happenings of one's life, which are reconstructed as a sequence of events in a story form. Because narratives are constructed retrospectively, they also reflect the ways in which the narrator has come to understand his/her own experience (Jacobson, 2001). While talking about one's personal experiences, a narrator end eavours to move from confusion and meaninglessness to greater clarity (Jackson, 1994). Thus, a life narrative is more than a simple description of past events. It is a process through which events are construed as having a meaningful and coherent order, through which events and experiences are interpreted, and through which the narrator acquires an identity, like a character in function (Good, 1994). Under conditions of adversity, individuals often feel a pressing need to re-examine and re-fashion their personal narratives in an attempt to mention a sense of coherence and identity. The self is, thus, reconstructed through narrative.

The narrative analysis respects and upholds this self of the narrator in responding to crisis predicaments in a creative manner. When a layperson constructs and communicates through the narrative of one's personal experience, one does so within cultural settings, which provide specific forms of language, values, role expectations, and modes of living. As Kelley (1994) has noted, "people develop a sense of self, and attempt to construct a public identity for themselves on the basis of the way they talk about coping”.

The narratives are compelling because not only do the narrators convey their emotional concerns, but they attempt to reorganize their experience, and wrest meaning from the same. 


\section{NARRATIVES OF SERO POSITIVE PERSON}

\section{Self narration of a Promulgator}

Positive reinterpretation and self actualization: A mission which turned an adversary in opportunity for transcendence.

Being positive, at the age of 30, I got an opportunity to understand realities of PLWHA [people living with HIV/AIDS] somehow with inner urge, I got a mission to live for positive person. An organization was formed named PPF [Positive people's foundations] with the assistance of community, government, and international and national agencies funding for HIV+ve persons.

Today, I am 39 years old and married to a negative woman. I wish to lead a purposeful life, where every single moment is dedicated to positive people in getting them need based counselling for transforming their life in positive direction. Our organization is also assisting positive people who are getting meaningful employment and other rehabilitation related facilities.

My wife is also a senior counsellor in MSF an international organization dedicated to positive persons and also part and partial of PPF. We know 'err is the human being' but the lesson one learns from them is valuable; hence a forgettable and one should also make other people realize about them.

I feel, that if people have strong will power, little obstacles do not refrain them from going ahead undaunted. Positive thoughts can make a person strong, who can easily over come big or small difficulties encountered in life. Like any other person, I take care of my health.

One cannot solve a problem by making it catastrophic, at the same time one may remember that when a problem is encountered it also brings solution, but it needs to be envisaged. Likewise when all the doors seem to be closed, there opens a passage to go out.

\section{Some Excerpts from interview from other sero positive person}

"It is not much important that how long we live, but it is rather more meaningful that how best we live.” Now I got “meaning” in the adversaries, firstly I accepted the reality that my daughters have to learn to live apart in order to get the opportunity for schooling.

Along with shouldering the responsibility of the family, she (HIV Positive) decided to join some organization to learn skills in living effectively with HIV and by becoming part of the organization, landed a helping hand for other positive persons. She earnestly felt the dire need of counselling for HIV positive persons and confidentiality be maintained in care canters. Services rendered to the clients should be based on their needs, when testing facilities are not easily available in Mumbai, what to say, rest of the country. 
There should be some policies and legislation for positive persons. If government had launched providing ART facilities in Mumbai it is rather a belated step and not a matter of pride. Stigma still persists in the society and people are either fired from the job or a compelled to leave due to HIV. Job security is a primary concern, however. She feels that so long as stigma persists within the positive persons it will remain outside, Therefore people should be bold enough to accept that they are positive and they will lead a positive life.

"One has to remember that she should not transmit the virus to other and forget the rest about the disease. Like a normal people be careful about health, eat, drink and be merry" we don't need sympathy but we need acceptance and support.

"My 5 years old daughter is not acceptable to my mother in law and lives in a 'Care Home'. It becomes most traumatic when she asks me to keep her in the home and desires to sleep with me.”

"It has become the mission of my life to become a ray of hope to positive persons (like myself) and to get resources available to them to the extent possible. I enjoy playing active role in support net work for the positive people.”

\section{IN-DEPTH ANALYSIS OF SOME CASE HISTORIES}

(All the names mentioned here are imaginary for confidentiality.)

Mina: A case of Positive Thinking, Cognitive Restructuring and Growth

Mina is a 30 years old, widow educated up to twelve standards, who shifted to Mumbai from Rajasthan after marrying with a migrated auto driver cum tailor master. Her husband was dead 3 years back with AIDS after prolonged illness. After detection of AIDS to her husband she was also diagnosed HIV positive. To her dismay, her 5 years old daughter also met the same fate. She was living with her in-laws in a joint family at the time of demise of her husband. Her mother in law did not allow keeping her daughters (even HIV negative one) at home. She was forced to keep her 5 years sero positive daughter in a rehabilitation centre and other is an orphanage, where their schooling is continued. However her mother in-law gladly allowed her grandson to keep at home. Economic crisis forced Mina to seek some employment; she is presently working as an HIV counsellor in positive people foundation [FADA] and in some other organizations. She also works as a social worker in the service of the HIV positive persons.

She is a warm hearted and highly sociable lady with very good social support network and one HIV negative intimate male friend with whom she shares her sorrow and joys.

As mina is an extrovert and posses dynamic and constructive outlook towards life, agreed to share her inner experiences willingly. While narrating the episodes of real life her face reflected the anguish, pain and emotional shocks, counter shocks born by her but at the end there was a smile of victory and success on her face. 
She still remembers the day when her heart was shattered in to pieces, listening an unsympathetic and rude voice from the Doctor to her husband that he had AIDS and likely to die in a month. Her tears dried, she could not even burst as she remembered the responsibilities left by her husband in his absence. She put heavy stones on her heart.

"In her case history, psychologically, the most distressing thing was that without any counselling the report of being positive was thrown on her husband with the prediction that he would die within a few month". In fact, his life was cut short by this shock punishment and even the remaining days were spent in counting the day of death as if the report was a death warrant. In fact her husband died due to broken heart not from illness.

\section{Accepting Reality, Positive Thinking and Emotional Regulation}

Mina sensed the void left by her husband and also accepted the reality of her sero positive status and also that her youngest daughter was also sailing in that same boat. Her mother in-law threw her granddaughter out of door, and she was there to combat the ravage. Under these situations, one can either melt or disappear or can come out stronger and did before.

It made her a much stronger person she literally felt that she could cope with anything, as she did not have anything more to lose. She felt to have an advantage over other people. She knew that there was a possibility that her life might not go on for as many years as other people are. She had opportunity to look at her life a fresh and make changes, so that she could lead the best not to count the days ahead. She tried to add life to rest of the years.

\section{Lalita: Social Support, Positive thinking, Healthy coping Strategies}

This is case history of 32 years old Marathi, Mumbai based female who is educated up to high school. Her husband died two years ago from AIDS. At the time of marriage he was having herpes but due to ignorance and lack of knowledge she did not recognize the danger signal. She was also tested positive. After death of her husband she was kicked by her in laws, who did not even think that her illness was a gift from their side. She was simply caught unaware; it was a catastrophic situation. At this critical juncture, a Gita came to rescue her and gave Shelter in her home for about a month.

\section{Positive Reinterpretation and Finding meaning}

As she relied deeply on her husband and therefore lost all faith on human being. But how long, she tried to accept the reality decided to live and search life and happiness in this situation, through Gita I came in touch with positive people foundation where I got friends like Mina and Heena. They were having very good support network of positive persons.

She got remained to a Gurgitation business man, whose sero positive status she did not like to disclose. She believes that in combating with HIV, inner strength and self confidence is more important. Life is precious and one has to learn to live like Roses who blossom among thorns. 
But this is only possible when one friends meaning in life and learns to live for greater purpose, so she decided to join PPF and work for positive persons.

\section{Observations}

"One should learn to live like Rose who blossoms among thorns".

"Life cannot be lived with tension, so one should learn to live by showing it with friends and intimate ones".

"Belief in God means believe in one self, at least there in some with whom one cam share everything."

My life is dedicated for the service of people like me. We must be united to get acceptance from the society. When do not hurt society, society should not hurt us. Positive person need economic independence and emotional support. Fresh food for body and fresh thought for mind.

She strongly advocated for HIV testing before massage. She also expressed concern for legislation by the government for protecting secure of HIV positive persons.

\section{Seema: A resilient lady}

Here is 32 years old widow, educated up to twelve standards and working in an office as assistant. Her husband was dead from the AIDS and she was also tested positive. She is undergoing treatment in FADA for ART. She has two children, a male and a female, after death of her husband and being tested positive, she feels helpless as she is not able to reveal her status to family members for the fear of ouster. She is also full of worried about future of her children after her death. She often feels depressed and loss of energy and enthusiasms towards life.

She is well aware with the efficacy of 'Dhyana' and 'Pranayam' but not able to do, so as she does not get up early in the morning. Her repression of status always makes her uneasy on conscious level, but cannot take the risk at all cost.

She has a lot of wishful thinking for doing so many things for her friends, family and children. She needs counselling to free her worried and overcome depression. But a silver line in her life is that she has an intimate male friend who is sero negative who is very supportive.

\section{Udyan: A Social deviant utter negligent towards health}

He has fantasy to be an AIDS counsellor and social worker till death but not actively involved in this venture. He has lost confidence in himself. He does not also have any direction in his life.

Udyan is a 35 years old Marathi youth in this symptomatic stage resides with his family he is educated up to $5^{\text {th }}$ standard. He is fearful about uncertainty and uncontrollability of imminent death. But due to unavailability and economic problems he has discontinued his ART since last one year and does not remember his CD 4. He has fined some social organization for social 
service where he casually visits. He became prey of the virus through Commercial Sex Worker (CSW). He shares his concerns with counsellors and a few friends.

\section{Uttam: PPF-A 'SAMRITAN' which infused new life}

Uttam is a 35 years old man, migrated from a Marathi village is educated up to $5^{\text {th }}$ standard. Earlier he was involved in some private business and earned 10 to 12,000 thousand rupees per month.

This much income was too much for a poor person, and he began spending in wine and women served. In fact, Mumbai's glamour made him dazzled and blind. Consequently after some fears his health began to deteriorate and finally, during treatment by semi qualified doctors, he was referred to government hospital, where he was declared HIV positive. During his sickness he had last all his saving and his earning was meagre. Now he resorted to country made were and footpath was his abode.

This case study reflects the dynamics through which a poor person who has not seen money, when gets surplus money, is driven by unconscious is impulses, and acts according to pleasure principle, devoid of control of ego and super ego. But then situation did not persist for too long, and after losing everything one day while he was lying on foot, perked by Ms Jaishree senior counsellor in MSF and on fee of HIV Ashay President of PPF. He was given Sheller in their home and treated for physical and illness and alcohol addiction.

He was given the job of watchmen, which he somehow manages. He is in symptomatic stage and suffering from T.B. and other opportunistic diseases. He is repenting on his earlier deeds; nothing else is left to be done.

He shares his emotional concerns only with PPF counsellors and serves positive persons to the best of his ability, with a missionary zeal.

\section{Bahadur: Crazy boy skids Deeper}

Bahadur is a 30 years old $5^{\text {th }}$ standard educated Nepali, migrated to Mumbai attracted by its glamour, in 1999 in search of employment. He did so against with of his parents. There he worked as watchman. Earlier, he was a very healthy man, free from any kind of sickness and had, high self concept. In a few years he was able to earn money up to his satisfaction, and got some amount spanned for luxury also. Being alone and surrounded by friends who visited C.S.W. regularly he also came across a girl who was familiar to him earlier. Being fully aware about the consequences of unprotected sex, he had 'optimistic bias', which made him, fall in to HIV trap.

After falling ill, he spent more than twenty thousand rupees on medicines prescribed by unqualified doctors. This shows the state of affairs, even in Mumbai. 
Bahadur perceived that he could not secure job which was compatible to his qualification, this sense of failure always put him in depression. HIV was the last nail in his coffin. However an important point in his case history is his dreams of speedy recovery, earning a lot of money and respect and desires to walk for positive persons. A man cannot be contended from happing and wealth, so therefore there is no point in obsessive thinking and creasing stress." He is also contended person as he says. He is concerned about medical facilities which are available at distant places; therefore people have to waste days together to get them. Poor people cannot afford to law leave of a few days and fall in the troop of unqualified doctors. Migrated people living alone are cut from the family and therefore deprived form love affection reasoned counselling and shock absorbers inbuilt in the family and culture. Therefore they become more valuable to stressors.

\section{Vivek and Sarika: Positive Couple in Symptomatic stage and psychiatric Disorders}

Vivek is a 37 years old Marathi young man who is technically educated and was earlier computer operator. But in the symptomatic stage of illness he was forced to leave job. He has become pray of many opportunistic diseases. Her wife is a government servant and tested positive also. They have one 6 years daughter, who is being looked after her grandmother. Her wife is suffering from severe depressed and often burst into anger.

Vivek is a gentle and humble person. One organization had displayed his close up in AIDS advertisement which irked him a suffered a lot of emotional distress too much. May be he could not understood the purpose of the consent asked for? But, this has resulted in to wide spread publicity, led her info to suffer a lot of ser organization. Prior to HIV testing Vivek was transfused blood twice and in local train once a man injected needle in this arm, which he could discover at home.

He is not certain about source of infection, but definitely it is not on his part. He has desire to form an organization for positive persons lest he gets support. His wife is also positive and having severe psychiatric disorders and swing between burst of anger and depressive phase.

\section{Meeta: A resilient Lady}

Meeta is 37 years old $8^{\text {th }}$ standard educated Marathi lady, whose husband was died from AIDS fever years ago. Subsequently, she was also tested positive.

In search of treatment she came across FADA, where she impressed the Doctor and other laboratory staff by her sociability, kind nature and helping habit. She was offered part time job of sweepers, which she readily accepted, there apart from her basic job also learned the skills of lab attendant and became a helping hand for lab technician Shree Madam, who is very much impressed with her. She shares all her concern with shree Madam.

She had 2 sons 16 and 11 years old. Wishes to life longer and see her children in good job. She is giving them good schooling and spend the lion's share of her saving on them. 
She has learnt counselling skills and facts prime satisfaction in infusing self confidence of other positive persons who come to FADA by giving her example. She is quite healthy even after 6 years of HIV testing. Infect, she lives for helping and instilling hope in desperate positive persons visiting FADA. Once when a positive woman with two children was kicked from home by mother in law, she gave shatter in her home for month and infused hope and confidence in her. Later she also become instrumental in getting her married with a business man who was also positive. It is a niece case of self from formation.

\section{Kumkum: A Negative Weds a Positive}

"Personal Growth and Active Coping with Social support for Emotional and Instrumental Reason”

I am 30 years old women with 3 years old female child. After death of my husband from AIDS, I became aware of my HIV status, at that time I was in third year of B. A. M. S., a medical course. I left my study in the beginning AIDS mode me feel like a poisoned dart, like I was a diseased person and I had no self esteem and no self confidence.

I had mode sure everybody known how I feel about them. I had withdrawn myself from the people around me. Even I had returned some gifts to people who gave them to me. Some people might not have them to me. Some people might not have appreciated it but it was relaxing to me. When something like AIDS happens to you, you can either melt or disappear or you come out stronger and victorious. I had decided to face whatever happens to me as being disparate and withdrawn, no longer helped me; suddenly I noticed a change in myself. I could not belief that I am somebody who once thought to end myself.

I had in mind about one of the NGO working for positive persons. I joined it for counselling which proved a turning point in my life. I also noticed, that one of my neighbour to whom I supplied Tiffin loved my daughter very much and inclined to develop inter personal relationship with me. Later he proposed me for life partner, and I accepted it without shadow to my daughter. He is a negative one.

Today I remember 'Is I am the same body who did not see any option than death to day I have recognized the value of life and want to make it more valuable. 'A man is tested in touch store of trouble' is a true saying.

I would like to live a purposeful life and give my hand to support positive people to march in positive direction. Thanks to PPF thanks noble persons like my husband. Time is a great healer.

\section{RESULT AND CONCLUSION}

This qualitative analysis was conducted to enrich understanding of how people work through emotional distress which culminates in self transformation and healing or other adjective reactions. Direct narration of persons, who had undergone through major life crisis was 
generated and analyzed, the path traversed in arriving a self healing, or reaching a workable adjustment with the situation.

One may try to find some psychological meaning from these findings. People are involved in risky behaviour while they are well aware with the consequences there of. They have optimistic bias, and interpret the instances in the light of probability. That everyone who is involved in unsafe sex is not prone to HIV.

Women are worst sufferer of HIV/AIDS epidemic, but stronger in positive coping with adversaries like death and bereavement they also take the challenges of child rearing while facing the brunt of stigma imposed on them in male dominated society . Positive cognitive restructuring and self regulation may lead to effective coping of HIV/AIDS epidemic.

\section{REFERENCES}

Bakan, D.(1968) Disease, pain and \& Sacrifice: toward a Psychology of Suffering, Chicago: University of Chicago press

Bonanno, G. A. (2001). Emotion self-regulation. In T. J. Mayne \& G. A. Bonanno (Eds.), Emotions: Current issues and future directions. New York: Guilford

Bradshaw, J. (1990). Homecoming-reclaiming and championing your inner child. Toronto: Bantam Books.

Dalai Lama (1992). Worlds in harmony. Berkeley, California: Parallax Press.

Frank, J.D. and Frank, J. B. (1984). Persuasion and healing. London: The John Hopkins University Press.

Good, B. J. (1994). Medicine, Rationality and Experience: an Anthropological Perspective. Cambridge: Cambridge University Press.

Jackson, H. and D. Civic. (1994). "Family Coping and AIDS in Zimbabwe”, Harare: Research Unit, School of Social Work.

Jacobson, N. (2001). Experiencing recovery: A dimensional analysis of recovery narratives. Psychiatric Rehabilitation Journal.

Jain, U. (1994). Sociocultural construction of emotions. Psychology and Developing Societies, 6,151-168.

Kakar, s.(1982). The inner world, New York: Oxford University Press.

Kelley, (1994), Handbook of self and identity, New York: Guilford

Misra, G. (2002). Emotion in modern psychology and Indian thought. Paper presented at the Conference on Yoga and Consciousness, Pondicherry, India.

Pennebaker, J.W.,Glaser, J.K., and Glaser,R.(1988)Discloser of trauma and immune function: Health implication for psychotherapy, Journal of consulting and clinical psychology. 56(2),239-245.

Siegel, B. S. (1991). Peace, Love and Healing. London: Allow Books.

Taylor, E. (1997). A Psychology of spiritual Healing. Pennsylvania: Chrysalis Books. 